\title{
PELATIHAN PEMBUATAN CASE GADGET CHEMISTRY STYLE YANG UNIK DAN KREATIF DALAM RANGKA MENINGKATKAN KETERAMPILAN MAHASISWA JURUSAN KIMIA FMIPA UNJ
}

\author{
Irma Ratna Kartika ${ }^{1)}$, Fera Kurniadewi ${ }^{1)}$, \\ Muktiningsih Nurjayadi $^{3)}$, Yuli Rahmawati ${ }^{4)}$ \\ Jurusan Kimia, Fakultas MIPA, Universitas Negeri Jakarta,
}

\begin{abstract}
ABSTRAK
Kegiatan pengabdian kepada masyarakat sebagai penerapan IPTEKS telah dilakukan di Jurusan Kimia FMIPA UNJ yang dihadiri oleh mahasiswa Jurusan Kimia sebagai tenaga potensial, dengan jumlah total peserta sebanyak 40 orang. Perumusan masalah utama pada kegiatan ini adalah: Bagaimana upaya konkrit untuk melatih keterampilan mahasiswa mendesain berbagai case gadget Chemistry Style dengan berbagai design unik dan kreatif yang terbuat dari resin sebagai upaya mengaplikasikan pengetahuan Kimia?

Tujuan dari kegiatan ini adalah: (1) Menambah dan mengembangkan wawasan pengetahuan Kimia para mahasiswa Jurusan Kimia tentang aplikasi resin; (2) Meningkatkan keterampilan kreatif mahasiswa dalam mendesain berbagai case gadget Chemistry Style dengan berbagai design unik dan kreatif yang terbuat dari resin. Program pengabdian kepada masyarakat ini diharapkan dapat memberikan manfaat: (1) Untuk menambah dan mengembangkan pengetahuan mahasiswa Jurusan Kimia FMIPA UNJ tentang resin dan aplikasinya dengan berbagai design unik dan kreatif untuk case gadget Chemistry Style; (2) Semua mahasiswa dapat mengembangkan kegiatannya menjadi lebih terprogram dan bernilai ekonomis; (3) Keterampilan yang diperoleh setelah mengikuti program ini diharapkan dapat dimanfaatkan untuk menciptakan lapangan kerja baru dan pada akhirnya dapat menambah penghasilan.
\end{abstract}

Kegiatan pengabdian kepada masyarakat ini dapat terlaksana dengan baik, karena: (1) Mahasiswa mengikuti setiap tahapan kegiatan yang diselenggarakan dari awal sampai akhir dengan sungguh-sungguh; (2) Mahasiswa aktif bertanya pada setiap tahap yang tidak dimengerti; (3) Mahasiswa berkeinginan untuk mengembangkan keterampilan yang diperoleh pada skala komersial yang bertujuan meningkatkan penghasilan; (5) Ketua Jurusan dan BEMJ Jurusan Kimia yang telah memberikan dukungan sehingga terwujudnya kegiatan dengan memberikan kemudahan dalam perizinan, himbauan pada mahasiswa dan penyebaran undangan.

Kata Kunci : Case Gadget, Chemistry Style, Resin, IPTEKS, unik dan kreatif, Kimia

\section{PENDAHULUAN}

Seiring dengan perkembangan teknologi di bidang informasi dan komunikasi, telah membuat masyarakat mengenal Imu Pengetahuan Alam lebih cepat, yang salah satunya adalah melalui penggunaan gadget yang berupa laptop, komputer tablet, dan ponsel.
Indonesia menempati urutan teratas di dunia dalam penggunaan ponsel pintar atau smartphone dengan waktu pemakaian rata-rata 181 menit per hari (Okezone, 2014). Sehingga, permintaan konsumen terhadap case gadgetakan meningkat, karena dengan case, gadget akan terlindungi dari guncangan dan mempermudah 
untuk dibawa. Case gadgetdapat berupa tas laptop, case tablet maupun case ponsel.

Seiring dengan perkembangannya, case gadget pun saat ini memiliki banyak variasi model dan design. Tetapi variasi model dan design case gadget yang saat ini ada di pasaran baru sebatas variasi pada warna dan design yang cenderung menggunakan tokoh kartun maupun animasi. Oleh karena itu, perlu adanya suatu inovasi yang unik dan kreatif dalam pembuatan model dan design tas laptop, case tablet, maupun case ponsel. Menginovasikan case gadget Chemistry Style dengan berbagai design menggunakan resin merupakan langkah strategis dalam memasarkanproduk case gadget yang unik dan kreatif. Case gadget yang khusus diperuntukkan bagi pelajar dan mahasiswa ini dibuat sebagai upaya mengaplikasikan pengetahuan dan wawasan Kimiakepada masyarakat, khususnya mahasiswa Jurusan Kimia FMIPA UNJ.

Berdasarkan kondisi ini, perlu diupayakan suatu kegiatan yang bertujuan untuk mendorong mahasiswa Jurusan Kimia untuk mengaplikasikan pengetahuan dan wawasan Kimia kepada masyarakat. Tujuan lainnya adalah untuk meningkatkan keterampilan mahasiswa dalam hal mendesain berbagai case gadget Chemistry Styledengan berbagai design unik dan kreatif yang terbuat dari resin, yang kemudian berguna untuk menambah penghasilan mereka bila dikembangkan dalam skala komersial.

\section{TINJAUAN PUSTAKA}

\section{A. Case Gadget}

Case gadget Chemistry Style terbuat dari bahan kain perca danbentuknya persegi panjang menyerupai bentuk gadget (laptop, tablet, dan ponsel) dengan berbagai design unik dan kreatif. Berbagai design unik dan kreatif tersebut di tempelkan ke case gadgetmenggunakan lem. Sementara, untuk tas laptop dibuat dengan tambahan resleting dan pegangan tangan untuk memudahkan membawa laptop. Sedangkan untuk case tablet dan case handphone dibuat variasi model soft case dan flip case.

Prospek pengembangan usaha case gadget Chemistry Styledikaji berdasarkan pada analisa
SWOT (Strength, Weakness, Opportunity, Threat) sebagai berikut :

1. Kekuatan (Strength) yang meliputi perkembangan teknologi yang canggih yang memudahkan setiap orang memiliki gadget; jumlah pelajar dan mahasiswa yang memiliki gadget cukup banyak di Indonesia; gadget perlu untuk dibuat tempat penyimpanannya atau sering disebut case gadget; variasi bentuk dan design yang memiliki keunikan tersendiri yang tidak didapatkan pada designcase gadget lainnya.

2. Kelemahan (Weakness) antara lain skala produksi yang masih relatif sedikit.Hal ini dapat diatasi jika adanya modal yang cukup besar.

Peluang (Opportunity) antara lain pelajar dan mahasiswa di Indonesia menggunakan gadget untuk kebutuhan informasi dan komunikasi; case gadget banyak diminati oleh kalangan pelajar dan mahasiswa untuk memudahkan membawa gadget; pemasaran dapat dilakukan melalui online shop dan sosial media agar semua orang mudah untuk mengaksesnya.

Ancaman (Threat) antara lain design produk yang rawan untuk diduplikasi/dibajak oleh oknum yang tidak bertanggung jawab serta munculnya usaha-usaha sejenis yang menggunakan design yang sama dan memproduksi dalam skala besar.

Berdasarkan uraian kelemahan (weakness) dan ancaman (threat) diatas, perlu disusun strategi untuk prospek pengembangan usaha case gadgetChemistry Styleagar lebih baik. Adpun strategi yang digunakan ialah dengan menggunakan kekuatan (strength) yang dimiliki untuk mengatasi kelemahan (weakness) dan ancaman (threat) yang ada. Ancaman dapat diatasi dengan caramembuat hak paten dari produk case gadget Chemistry Style. Berdasarkan uraian analisa SWOT diatas dapat diprediksi bahwa pengembangan usaha ini akan mendapat sambutan yang baik serta memiliki prospek usaha yang baik pula. 


\section{B. Resin}

Resin adalah senyawa polimer rantai karbon. Polymer berasal dari kata -poly (banyak) dan -mer (ikatan). Senyawa polimer rantai karbon dapat didefinisikan sebagai senyawa yang mempunyai banyak ikatan rantai karbon. Resin merupakan bahan pelapis, perekat dan material komposit seperti yang menggunakan serat karbon, serta pembuat fiberglass (meskipun polyester, vinyl ester, dan resin thermosetting lainnya juga digunakan untuk plastik yang diperkuat kaca). Resin berwujud cairan kental seperti lem, berkelir hitam atau bening, menyerupai minyak goreng, tetapi agak kental. Ada banyak jenis resin, diantaranya adalah: Natural Oil, Alkyd, Nitro Cellulose, Polyester, Melamine, Acrylic, Epoxy, Polyurethane, Silicone, Fluorocarbon, Venyl, Cellolosic, dan lain-lain.

Resin atau epoksi terdiri dari monomer atau polimer rantai pendek dengan kelompok epoksida di kedua ujung. Epoksi bersifat adhesi dan tahan panas, sifat mekanik, dan sifat isolasi listrik. Resin paling umum yang dihasilkan adalah berasal dari reaksi antara epiklorohidrin, bisphenol-A dan monomer polyamine, misalnya triethylenetetramine (Teta). Ketika semua senyawa dicampur bersama, kelompok amina (NH) bereaksi dengan kelompok epoksida untuk membentuk ikatan kovalen menghasilkan polimer sangat silang, kaku dan kuat. Proses polimerisasi disebut "curing", dan dapat dikontrol melalui suhu, pilihan senyawa resin, dan rasio konsentrasi senyawanya; dan lamanya reaksi.

Resin berfungsi untuk mengeraskan semua bahan yang akan dicampur. Resin biasanya digunakan sebagai bahan dasar dalam

membuat kerajinan, dan gantungan. Resin jenis butek lebih banyak digunakan untuk pembuatan aksesoris, disamping harganya murah, resin ini dapat dengan mudah dibeli di toko-toko kimia.

Resin untuk bahan aksesoris fiberglass, umumnya menggunakan resin bening atau resin butek. Resin bening, biasanya digunakan untuk bentuk yang menonjolkan kebeningannya, seperti untuk aksesoris visor, kap lampu dan lain lain sebagai pengganti mika, namun penggunaan resin bening yang ada di pasaran untuk pengganti mika, masih belum menghasilkan kualitas yang memuaskan.

Cairan katalis biasanya berwarna bening dan berbau agak menyengat. Cairan ini berfungsi untuk mempercepat proses pengerasan adonan fiber. Semakin banyak katalis maka akan semakin cepat adonan mengeras tetapi hasilnya kurang bagus. Katalis dibutuhkan dalam jumlah relatif sedikit. Penggunaan katalis $1 \%$ dari resin dalam kondisi dingin. Namun, jika cuaca panas, katalis yang digunakan hanya $0.8 \%$ dari resin. Cairan ini jika mengenai kulit akan terasa panas, seperti cairan air aki. Kalsium karbonat yang berbentuk bubuk putih yang menyerupai terigu ini berfungsi sebagai pengental adonan fiberglass.Semakin banyak campuran kalsium karbonat pada adonan, maka hasil fiberglass akan menjadi lebih tebal dan berat. Bahan ini dapat diganti dengan talc, tetapi warna talc agak lebih gelap.

\section{Kerajinan Tangan Dari Resin}

Langkah-langkah dalam membuat desain antara lain dengan:

1. Membuat visualisasi produk dengan gambar melalui komputer. Melakukan pembuatan pola melalui komputer yang kemudian dituangkan dalam gambar desain. Hal ini bertujuan memvisualisasikan desain prosuk yang akan dibuat dan mempermudah dalam pencetakan.

2. Membuat cetakan fiberglass sesuai ukuran gambar. Gambar produk yang telah dibuat kemudian digunakan untuk menciptakan cetakan fiberglass dengan ukuran tertentu. Cetakan ini dibuat dari bahan fiberglassuntuk mempermudah pembentukan.

3. Finising desain cetakan fiberglass. Finising dilakukan untuk melihat keakuratan ukuran dan kesesuaian bentuk cetakan dengan model gambar.

Adapun, proses pencetakan dilakukan dengan beberapa tahapan, yaitu:

1. Menyiapkan alat-alat berupa gelas air mineral atau baskom atau ember, pengaduk (bisa sumpit atau sendok plastik), dan sarung tangan. 
2. Menuang resin, katalis dan talc kedalam gelas air mineral dengan perbandingan campuran Resin : Katalis $=1$ liter : 10cc $(0,01 \mathrm{~L})$, sedangkan resin ditambah talc kira-kira perbandingan 1:1. Untuk mengetahui apakah resin dan katalisnya sudah benar-benar tercampur, maka ketika campuran diaduk, resin dan katalis akan terasa lebih sukar diaduk atau sudah lebih lengket. Bila katalis terlalu banyak dicampurkan pada resin, pada saat sudah kering, resin akan menjadi retakretak. Bila katalis terlalu sedikit sedikit dicampurkan pada resin, resin akansulituntukmongering.

3. Penambahan air secukupnya untuk menjaga agar bahan baku tidak mudah mengeras.

4. Penambahan pigmen sesuai warna yang dikehendaki dan diaduk-aduk sampai merata.

5. Penuangan bahan baku kedalam cetakan dan menunggu hingga mengering dan keras. Sebelum cetakan digunakan, terlebih dahulu diolesi dengan minyak goreng agar resin yang sudah kering mudah dilepas dari cetakan.

6. Mengeluarkan fiberglass dari cetakan.

7. Untuk pemberian hiasan, resin yang sudah diaduk dan tercampur dengan katalis, dimasukkan kedalam cetakan (yang sudah diolesi minyak goreng) hanya setengah cetakan terlebih dahulu. Resin ditunggu sampai agak mengering, lalu hiasan dimasukkan. Hiasan dapat berbentuk potongan kecil kertas warna, daun dan bunga atau foto, uang recehan pecahan 100, 200, atau 50 rupiah, bubuk atau pasir warna. Hiasan dijaga agar tidak ikut mengapung diatas campuran resin dan katalis.

\section{METODE PELAKSANAAN}

Tahap Pendahuluan meliputi pengumpulan data mengenai karakteristik mahasiswa Jurusan Kimia FMIPA UNJ, jenis dan merek gadget yang dimiliki oleh mahasiswa, case gadget yang selama ini digunakan oleh mahasiswa, mengadakan koordinasi dengan Ketua Jurusan dan Ketua BEMJ dalam hal penyesuaian waktu dengan kelompok sasaran.
Persiapan antara lain penyusunan rencana kerja yang meliputi persiapan penyuluhan, penyusunan materi penyuluhan, persiapan alat dan zat untuk resin, serta mengatur waktu dan tempat kegiatan penyuluhan.

Pelaksanaan kegiatan ini telah dilakukan dalam satu kali pertemuan, yaitu pada hari Senin, 5 Oktober 2015 pukul 08.00 - 12.00 WIB, bertempat di Ruang 1.6 - 1.7 Gedung FMIPA UNJ dengan jumlah peserta sebanyak 40 orang.

\section{HASIL DAN PEMBAHASAN}

Peserta memberikan tanggapan yang positif dan antusias pada kegiatan ini. Peserta banyak mengajukan pertanyaan karena keingintahuan lebih lanjut peserta mengenai informasi yang telah disampaikan. Beberapa pertanyaan dari peserta antara lain:

a. Jenis resin yang digunakan,

b. Komposisi dan perbandingan campuran resin : katalis : talc,

c. Penggunaan bahan pengganti katalis dan talc,

d. Kemudahan mendapatkan bahan (resin, katalis dan talc),

e. Harga bahan yang digunakan (resin, katalis dan talc),

f. Penyimpanan dan daya tahan produk yang dihasilkan,

g. Keamanan produk untuk digunakan oleh semua umur (anak-anak, remaja, dewasa, dan manula),

h. Fungsi produk yang dihasilkan.

Tim pelaksana juga mengadakan wawancara kepada peserta kegiatan tentang program kegiatan yang telah dilaksanakan untuk mengetahui kebermanfaatan kegiatan. Berdasarkan hasil wawancara dengan peserta kegiatan, program pelatihan ini dianggap sangat bermanfaat karena:

a. Mahasiswa Jurusan Kimia FMIPA UNJ dapat menambah dan memperluas wawasan pengetahuan mereka tentang teknologi tepat guna bidang kimia terapan yang sederhana. 
b. Mahasiswa Jurusan Kimia FMIPA UNJ dapat menambah keterampilan.

c. Mahasiswa Jurusan Kimia FMIPA UNJ merasa terpacu untuk menghasilkan produk yang unik dan menarik dan dapat dikembangkan dalam skala komersil.

Mahasiswa Jurusan Kimia FMIPA UNJ yakin bahwa keterampilan yang diperoleh setelah mengikuti kegiatan ini dapat diterapkan dan dimanfaatkan langsung setelah mengikuti kegiatan untuk menciptakan lapangan kerja baru dan pada akhirnya dapat menjadi sumber penghasilan.

Kegiatan pengabdian kepada masyarakat ini dapat terlaksana dengan baik, karena:

a. Peserta mengikuti setiap tahapan kegiatan yang diselenggarakan dari awal sampai akhir dengan sungguh-sungguh,

b. Peserta aktif bertanya pada setiap tahap yang tidak dimengerti,

c. Peserta berkeinginan untuk mengembangkan keterampilan yang diperoleh pada skala komersial yang bertujuan meningkatkan penghasilan,

d. Ketua Jurusan dan BEMJ Jurusan Kimia memberikan dukungan sehingga terwujudnya kegiatan dengan memberikan kemudahan dalam perizinan, himbauan pada mahasiswa dan penyebaran undangan.

\section{KESIMPULAN}

Kesimpulan kegiatan pengabdian kepada masyarakat ini adalah:

a. Peserta kegiatan telah mampu membuat design dan membuat Case Gadget Chemistry Style yang unik dan kreatif,

b. Peserta memberikan tanggapan yang positif dan antusias pada kegiatan ini.

c. Untuk mengetahui kesungguhan peserta dalam menerapkan pengetahuan dan keterampilan yang diperoleh selepas mengikuti kegiatan, maka perlu adanya pembinaan yang berkelanjutan dan kontinue, d. Peserta perlu diberikan penyuluhan lanjutan tentang pembuatan kemasan produk yang menarik bagi konsumen,

e. Peserta perlu diberikan penyuluhan lanjutan tentang cara penyimpanan produk yang telah dibuat agar tahan lama,

f. Peserta perlu diberikan penyuluhan lanjutan tentang strategi pemasaran produk yang telah dibuat kepada masyarakat,

g. Peserta perlu diberikan penyuluhan lanjutan tentang analisis usaha yang akurat untuk melihat prospek usaha yang akan dilakukan dan disesuaikan dengan kondisi saat ini.

\section{DAFTAR PUSTAKA}

Hightower, R. and Gradecki, J. D. 2003. Mastering Resin. Indiana: Wiley Publishing Inc.

Kelompok Kerja Pengembangan Sumber Daya Manusia, 1996. Profil Teknologi Padat Karya.

May, C. A. 1988. Epoxy Resin: Chemistry and Technology. Second Edition. New York: Marcel Dekker Inc.

Sanggarang, D. L. 2004. Membuat Kerajinan Berbahan Fiberglass. Jakarta: Kawan Pustaka.

E. Sutrisno, C. I., 1998. Metode dan Bentuk Pengabdian Masyarakat. IKIP Jakarta. 